\title{
DIREITO AOS BENS CULTURAIS NA INFÂNCIA: O LIVRO LITERÁRIO COMO INSTRUMENTO INTELECTUAL E AFETIVO
}

\author{
DIANE VALDEZ \\ Universidade Federal de Goiás (UFG), Goiânia, Goiás, Brasil
}

\begin{abstract}
RESUMO: Este texto discutirá a relação da infância com a literatura em sua natureza estética e artística, enquanto um bem social, como um direito de todas as crianças, a despeito da idade, classe social, etnia, entre outros. Pretende-se trazer, para o debate, movimentos considerados próprios da infância que não incluem o livro literário no cotidiano, naturalizando-o como um objeto sisudo e distante da vivacidade infantil. Atenta-se ainda para os aspectos pragmáticos que envolvem o fazer literário, validando ações objetivas, com efeitos deterministas e moralistas. Neste sentido, o direito ao livro se faz diluído sob efeitos de um objeto visto mais como redentor e menos como interação em um movimento diversamente complexo e contraditório no mundo da criança.
\end{abstract}

Palavras chaves: Livro. Literatura. Infância. Direito. Bem social.

INTRODUÇÃO

Não é raro o estabelecimento de padrões voltados para a criança' quando se refere ao livro e a suas formas de acesso. Normas e regras fixas são lembradas continuamente para evitar possibilidades de estragar, sujar, rasgar ou manusear do jeito infantil. No ambiente escolar e doméstico, quase sempre, os livros são alçados em distâncias construídas historicamente, ampliando o fosso que separa a criança do livro. Proporcionar livros como 
presentes, espalhar livros em consultórios, hospitais, ônibus, praças ainda são movimentos raros em nossa sociedade.

Sob as mãos de adultos, se contam os livros sob critérios e recortes estabelecidos previamente, certamente que a intervenção adulta é necessária no processo educativo. No entanto, este texto pretende trazer outros elementos como possíveis protagonismos infantis diante de valores quase cristalizados no acesso ao objeto livro em suas distintas formas, cores e gêneros. A narrativa oral não será desconsiderada, até porque as ressonâncias e variadas reações do livro via adultos, transmitindo histórias e conhecimentos ao mundo infantil, parecem ser tão importantes quanto outros movimentos em torno do amplo direito à literatura. No entanto:

Para nós, o livro precisa ser apresentado à criança como um patrimônio cultural a partir de duas dimensões: material e literária. A dimensão material inclui o livro como objeto: seu formato, seu tamanho, sua disposição gráfica, sua materialidade. A criança precisa entender que ali existe uma (ou mais) história(s), contada(s) por uma linguagem; que há necessidade de seguir a sequência das páginas; que o livro tem um lado certo de ler; que é preciso iniciar a leitura da página esquerda para a direita, de cima para baixo; que as ilustrações precisam ser lidas em coerência com o texto escrito; que o livro não é feito para ser colocado na boca; que é preciso ter cuidado, pois o material costuma ser frágil; que um livro pode ser lido mais de uma vez etc. Nesse sentido, cabe ao professor planejar um trabalho de manipulação desse objeto cultural em que a criança possa pegar, sentir, folhear o livro, tendo o educador como modelo leitor e como mediador do processo (SOUZA; MARTINS, 2015, p. 235).

A despeito de haver consenso sobre a importância dos livros para o desenvolvimento infantil, garantir os livros nas mãos da pequenada permanece uma conversa a ser realizada, apesar dos avanços presenciados, já que nos:

...anos 70 e o início dos 90 do século XX ficaram conhecidos como a época do boom da literatura para crianças no país, e hoje este fenômeno já é totalmente assimilado. Multiplicaram-se os estudos e análises a respeito, tanto os incidentes sobre o conjunto de autores e as principais tendências de livros publicados, como os que puseram foco sobre os escritores individuais, objeto de estudo em diferentes faculdades (MACHADO, 2008, p. 14).

Diante do movimento favorável das obras literárias, conforme registrou Machado, indaga-se sobre formatos que pareciam ter ficado no passado, mas, quando se refere à democratização de livros, ainda se fazem vivos no presente: que argumentos os mantêm bem guardados em 
armários, fora do alcance da criança, ainda que a compra dos livros tenha sido concretizada com verba pública? Que formatos estabeleceram o público infantil como incapazes de tomar os livros nas mãos para folhear, cheirar, tocar, apontar e construir relações afetivas com o livro? Como os livros são formatados nas relações vividas pela infância, seja no lazer, seja no aprender informal ou escolar? De que formas os livros chegam para as infâncias nas próprias obras literárias?

São questões grandes e complexas para abordar em um só artigo, no entanto, ainda que sob formato de riscos generalizatórios, tentarei argumentar aqui em defesa da criança e de seu acesso à literatura, assim como de outros fenômenos artísticos de comunicação, como um direito inalienável, como bem expressou Oliveira (1008, p. 31): "A arte não é uma esfinge, mito indecifrável de acesso a uma elite de exegetas." Então, por que insistirmos em manter os bens literários disponíveis para uma minoria, mesmo que os livros estejam adquiridos?

Argumentarei sobre a pequenada ter livros em mãos, em casa, na escola e em outros espaços, na perspectiva do direito de tê-los, seja de forma individual ou coletiva, assim como o direito de viver a literatura sem fins pragmáticos e sisudos. Trata-se de um direito o acesso a este material, complexo e diverso, que insiro no campo poético de diferentes culturas, sem restrições.

\section{LUGARES E TEMPOS LITERÁRIOS: O DIREITO AO LIVRO NAS PÁGINAS DE NOSSAS INFÂNCIAS}

Falar sobre o direito da infância aos bens culturais produzidos pela humanidade, como o livro, parece ter sentido somente em um contexto não tão afastado do tempo, pois, historicamente, livros eram objetos para poucos homens sisudos, religiosos, intelectuais e limitados proprietários de letras desenhadas em couro, papiros e caros papéis:

[...\} se a invenção da escrita se situa no terceiro milênio antes de nossa era, o livro impresso demorou mais de quatro mil anos para surgir e permitir, às camadas cada vez mais amplas, um conhecimento até então reservado apenas a elite privilegiadas (MINDLIN, 1992, p.1).

Antes da invenção da imprensa, as folhas com textos pintados de tintas eram costuradas e formatadas para cumprir funções de gente reconhecida como ilustrada. Pensar em livros específicos para crianças na história da educação, seja doméstica ou escolar, é pensar com o que o tempo histórico permite. A categoria, que hoje identificamos como literatura 
infantil, é recente, visto que nem mesmo os contos de fadas, antes do período oitocentista, eram pensados ou estavam disponíveis somente para crianças.

A relação da criança com o objeto livro foi instalada de forma mais concreta, sobretudo, a partir do século XVIII. Percebe-se esse movimento pelo número de obras impressas para o público infantil, sobretudo, manuais civilizatórios, catecismos, livros de imagens e livros de leitura. A iconografia de crianças nobres e burguesas retratava-as em pinturas com objetos diversos, que foram substituídos, após o movimento iluminista, por livros, indicando que a relação infância e livro enquanto dispositivo clássico estava se instalando².

Falar em direitos da infância, garantidos pela legislação, é muito recente, o Estatuto da Criança e do Adolescente (ECA-1990), reconhecido como um avançado dispositivo de garantia de proteção integral dos direitos da infância e adolescência, determina direitos que não são para'o menor', mas para todas as crianças e adolescentes. Em seu Capítulo V, o ECA destaca o direito à educação, à cultura, ao esporte e ao lazer e registra o livre acesso aos níveis mais elevados do ensino, da pesquisa e da criação artística, garantindo a liberdade de criação e o acesso às diferentes fontes de cultura.

Candido, em seu texto "O direito à literatura", escrito em 1988 (imensamente atual), lembrou que, de forma quase natural, concordamos e defendemos o direito às necessidades básicas como educação, saúde, alimentação, lazer, no entanto, não consideramos direito essencial a apropriação de todas as formas de cultura, como a arte ou a literatura. $O$ autor provoca a respeito da forma em que pensamos nossos direitos:

Porque pensar em direitos humanos tem um pressuposto: reconhecer que aquilo que consideramos indispensável para nós é também indispensável para o próximo. Esta me parece a essência do problema, inclusive no plano estritamente individual, pois é necessário um grande esforço de educação e autoeducação a fim de reconhecermos sinceramente este postulado. $\mathrm{Na}$ verdade, a tendência mais funda é achar que os nossos direitos são mais urgentes que os do próximo (CANDIDO, 1988, p. 172).

Ao alertar sobre a complexidade do mundo literário, Candido defende a literatura, seja clássica ou popular, para todos, alertando que ela não corrompe nem edifica, mas tem o papel de humanizar, pois faz viver emoções e visões de mundo dentro de um conhecimento difuso e inconsciente. Para este crítico literário, o universo da ficção e poesia constitui-se como um direito no sentido universal da sociedade, um instrumento intelectual e afetivo, que é indispensável, pois a literatura, com todas as contradições, confirma, nega, propõe, denuncia, apoia, combate, etc. 
A literatura, para o sociólogo e literato, como a própria vida, não é inofensiva, no entanto, é uma necessidade universal e desfrutá-la é um direito de todas as pessoas. Ao defender a literatura como humanizadora, o autor a toma como um processo que confirma no homem traços essenciais, como a penetração nos problemas da vida e a percepção da complexidade do mundo, seja na afinação da emoção, na permissão de cultivar reflexão, no adquirir do saber, na disposição da beleza, conflito, humor, etc.

Compactuamos com Candido a extensão da literatura a todos como um direito humano. No entanto, nosso foco é a criança, pessoa em formação, sob a responsabilidade de adultos. As conquistas legais de direitos básicos para a infância se fizeram sob muita resistência e luta por parte da sociedade civil, e ainda há muito para ser feito, sobretudo no tocante às questões sociais que separam o acesso aos direitos de muitos meninos e meninas.

No que se refere ao direito a bens culturais, não parece apropriado esquecer que a concepção de criança ainda vale como medida para negar direitos que parecem pertencer ao mundo do adulto, como os livros. Neste aspecto, o item da liberdade de escolha, da apropriação e expressão de gostos pessoais fica ainda mais comprometido:

A literatura, assim como as manifestações artísticas em geral, é também um meio de expressão que trata das mais diversas questões humanas, dentre elas a liberdade. A liberdade de expressão é inerente à literatura, que, por meio do plano ficcional, aborda temas como: felicidade, tristeza, vida, morte, amor, ódio, riqueza, pobreza, autoridade, obediência, liberdade, submissão, espírito, matéria (SOUZA; MARTINS, 2015, p. 225)

Pensar a criança como sujeito de direitos e negar a liberdade de acesso ao livro, julgando-a incapaz, não parece contraditório? Reconhecer na criança a capacidade subjetiva de tomar o livro como um objeto múltiplo não seria um caminho para romper com normas que separam a infância do livro? Aprender e praticar a escolha de gêneros, autores, formatos e outros não seria um ato de liberdade a ser praticado? São questões que precisam ser experimentadas. Entretanto, ficam as perguntas para serem confrontadas.

\section{LEITURAS COMPROMETIDAS COM SABERES DETERMINADOS: O LIVRO COMO OBJETO DE REDENÇÃO}

A despeito da polêmica do que se deve ou não oferecer para a criança ler, parece difícil ignorar ou reduzir a importância do livro literário no desenvolvimento infantil. Não é raro defender o acesso da criança à literatura de forma pragmática, com funções quase sempre didáticas e definições 
fechadas. Cito, a seguir, alguns apontamentos amadurecidos nas pesquisas e nas vivências de autora de livros para crianças:

1. persiste no ambiente escolar e em outros ambientes a perspectiva do acesso ao livro enquanto portador de orientações evidentemente morais e religiosas capazes de combater vícios e exaltar virtudes;

2. investir, desde a tenra idade, no acesso ao livro para proporcionar conhecimentos, em especial o aprendizado da leitura para se 'tornar' leitor/a;

3. facilitar o acesso às obras que auxiliem na compreensão de conceitos didáticos específicos, fazendo da obra literária extensão do livro didático.

Essa determinação salvadora imposta ao papel moralizador e redentor das páginas literárias não ficou no século XIX. Prova disso é a insistência na compreensão'positiva' da produção de bons cidadãos a partir delas. Isso pode estar associado à ideia cristalizada de infância que persiste: um ser impotente, não apto em sua subjetividade e na complexidade humana. Acreditar que a literatura pode fazer intervenções diretas na criança a partir do que o adulto crê, como combater os vícios e exaltar as virtudes, é ignorar a complexidade dos livros e da vida.

Ter acesso a livros que divulgam e pregam consideradas bondades não fará um mundo mais altruísta, pois este e outros temas não se ensinam, ou se mensuram, por meio do livro literário, mas sim pelas experiências sustentadas pelos direitos humanos de forma crítica e constante:

Por isso é que nas nossas sociedades a literatura tem sido um instrumento poderoso de instrução e educação, entrando nos currículos, sendo proposta a cada um como equipamento intelectual e afetivo. Os valores que a sociedade preconiza, ou os que considera prejudiciais, estão presentes nas diversas manifestações da ficção, da poesia e da ação dramática. A literatura confirma e nega, propõe e denuncia, apoia e combate, fornecendo a possibilidade de vivermos dialeticamente os problemas. Por isso é indispensável tanto a literatura sancionada quanto a literatura proscrita; a que os poderes sugerem e a que nasce dos movimentos de negação do estado de coisas predominante (CANDIDO, 1988, p. 175).

A literatura como equipamento intelectual e afetivo, como registrou Candido, parece apropriada ao que chamo aqui de apostar e investir 
na vivacidade da infância. Diferente da tradição de condenar a criança aos mesmos caminhos reconhecidos e consagrados, os aspectos das subjetividades intelectuais e afetivas podem desmistificar práticas e valores de intocabilidade, de página intangível, que afetam o acesso das mãos e olhares dos pequenos.

O uso da obra literária como instrumento didático parece ferir a própria composição deste objeto, a despeito da literatura, ao adentrar na escola, se tornar mais um elemento didático, creio que seu desempenho pode escapar da pura escolarização. Neste aspecto, o direito ao livro de forma coletiva, como atividade social, pode ajudar a construir os espaços entre as crianças no mundo. Escutar, ler, falar sobre, construir sentidos e conhecimentos, fazer circular e socializar contos literários por meios de contação de histórias, murais convidativos, saraus, festivais, rodas, pode fazer das narrativas lugares humanizadores, lugares de afeição, espaços de ajudar a compreender melhor o outro.

Exigir conceitos herméticos, oferecidos antes dos livros, pode impedir uma das ações indispensáveis do mundo literário, a substituição da realidade por aventuras imaginárias, o que Aguiar chama de fabulação:

A capacidade de fabulação é uma qualidade universal dos seres humanos, embora ela possa - e até deva - se manifestar de formas diferentes em diferentes culturas. Ela é como o sonho: indispensável. Portanto, por essa dimensão, ela é um direito, e, como tal, um direito inalienável do direito ao exercício da liberdade, do direito de ter e exercer direitos. De certo modo, ela é um "ur-direito", um direito primevo, porque é através do exercício contínuo da fabulação que podemos abrir o pensamento e as emoções para a imaginação de outros mundos possíveis, e portanto, assim, começar a transformar este em algo melhor. [...] De qualquer modo, olhando esta faculdade e esse direito de um ponto de vista positivo, também é através dos processos de fabulação que começamos a ver o mundo e a nós mesmos com os olhos de outrem, abrindo o espírito para as aventuras das transformações (AGUIAR, 2012, s.p.).

Dar abertura para as transformações de mundos possíveis, isso pode nos transmitir algo caro que já é indicado na própria expressão 'literatura infantojuvenil'. Ou seja, o que sustenta a proposta deste material é a literatura, não obstante se o público a quem se dirige é considerado frágil, incompleto, precoce, etc. Não parece viável esquecer esse fundamento essencial, o que pode possibilitar contextualizar melhor o objetivo de obras fundamentais na formação das crianças. 
LIVROS E BRINQUEDOS: FRONTEIRAS PRODUZIDAS NATURALMENTE

Agora é hora de brincar e livro não é brinquedo!

Não? Eu achava que era...

(R.T.L. - quatro anos)

A epígrafe sobre a indagação de uma criança sobre livro e brinquedo, extraída da experiência de uma professora em um Centro Municipal de Educação Infantil de Goiânia, me fez refletir a respeito do que se consideram direitos assimilados para a infância. Brincar é um direito reconhecido, tanto que há inúmeras pesquisas que apontam a necessidade de brincar na infância. Diante disso, pareceu ser relevante observar o movimento de brinquedos feitos para a infância e sua relação com os livros.

A produção histórica de brinquedos em formato de personagens, bonecas, apetrechos, jogos e outros parece ignorar o objeto livro em seus contextos. O sistema de produção e de consumo não prioriza páginas com letras em detrimento de armas, carros, apetrechos culinários. Uma boneca leitora parece não atrair tanto como a boneca dona de casa ou mãe com equipamentos próprios ou, em um super-herói encarregado de salvar o mundo, não cabe um livro no lugar de armas de raios. Desconheço entre os móveis infantis, para compor uma miniatura de casa, estantes e livros.

Descartada a possibilidade de brinquedos trazerem em suas conexões pistas de obras literárias, ainda que de forma rápida, é possível pensar três questões sobre isso: a primeira é que os livros não se integram e nem se constituem como objetos de consumo no interior do mundo de lazer oferecido aos pequenos. A segunda questão leva a pensar que o direito ao brincar, neste caso, está mais naturalizado do que o direito ao livro, é só conferir o número de lojas de brinquedos e de livrarias. A terceira é que o brincar não necessita de intervenção de adultos como se faz com os livros literários, ou seja, os brinquedos acompanham as crianças sem porta-voz.

O livro não acompanha a diversão, parece algo sisudo, distante da possibilidade de entreter, longe de virar objeto de brincos, como registrou Lygia Bojunga Nunes em seu texto "Livro: a troca":

Pra mim, livro é vida; desde que eu era muito pequena os livros me deram casa e comida. Foi assim: eu brincava de construtora, livro era tijolo; em pé, fazia parede, deitado, fazia degrau de escada; inclinado, encostava num outro e fazia telhado. E quando a casinha ficava pronta eu me espremia lá dentro pra brincar de morar em livro. De casa em casa eu fui descobrindo o mundo (de tanto olhar pras paredes). Primeiro, olhando desenhos; depois, decifrando palavras. Fui crescendo; e derrubei telhados com a cabeça (NUNES, 1989, p.1). 
Relacionar o livro ao entretenimento parece ter mais lacunas do que debates. Claro que não se trata de algo simples, no entanto, parece ser importante tratar de direitos em um formato amplo. Em seu livro Os direitos das crianças, a escritora Ruth Rocha (2014) lança mão, em um formato bemhumorado, dos direitos da pequenada e, na mesma ordem de exigência, inclui ser bem-cuidada, brincar, viajar, falar, comer, calar, assim como ter livros, revistinhas, ouvir histórias, etc.

Em seu texto "Livros", Benjamim narra, minuciosamente, seu acesso aos livros da biblioteca escolar em sua infância. A estrutura dos livros, não escolhidos por ele, é assim registrada:

Em suas folhas estavam grudadas marcas de dos dedos que as haviam manuseado. $O$ cordel que fechava a cabeçada e que salientava em cima estava sujo. Porém, a lombada é que devia ter sofrido mais abusos; dai o fato de ambas as capas saírem do lugar e de a borda formar degraus e terraços (BENJAMIM, 1995 p. 113).

Os livros que formaram as casas e as páginas que fizeram degraus e terraços de Lygia e Benjamim (adultos falando de suas infâncias) não parecem se estender como divertimentos comuns. Assim como não se inclui o livro nos direitos básicos da criança, conforme a escritora Ruth Rocha registrou. Evidentemente que o alcance das crianças às páginas e ilustrações dos livros literários é grande e parece imensurável. O que parece importante nos aspectos trazidos nesta parte do texto é perceber a ausência da literatura quando se refere às atividades de lazer em práticas reinantes no mundo infantil. Isso poderia ser uma pista de este material se adequar mais ao sisudo mundo escolar do que pertencer ao cotidiano do lazer?

\section{Personagens literários e as trocas com os livros: Bela, Cora e Clarice}

Diante do movimento entre a não apropriação do livro enquanto um objeto integrado ao mundo de lazer, optei por trazer nesta parte como o livro é tratado na própria literatura produzida para crianças e que as envolve. Se a literatura a qual nos referimos está disposta para este público, como o objeto livro está disponibilizado para elas em alguns fragmentos recortados?

Escolhi a produção de três mulheres autoras de diferentes tempos: a francesa Jeanne-Marie Leprince de Beaumont, que escreveu A Bela e a Fera (1756), a ucraniana de brasilidade pernambucana Clarice Lispector, com seu texto Felicidade clandestina (1971), e a goiana de Vila Boa de Goiás Ana 
Guimarães Lins Peixoto - Cora Coralina -, com seu poema "Meu melhor livro de leitura" (1987).

Seguindo o tempo histórico das produções, em A Bela e a Fera, a protagonista é caracterizada não somente pela humildade, gentileza, delicadeza e generosidade, características naturalizadas no mundo feminino dos contos, mas sim pelo seu gosto, considerado 'estranho', pelas ciências e pelos livros. Transformada em filme, pelos estúdios Disney (1958), a animação apresenta Bela, a adolescente de olhos curiosos que, ao contrário de outras plebeias candidatas ao trono, não manifestava preferência por bailes, roupas douradas, casamentos ou carruagens. Desejava uma biblioteca com muitos livros e, a despeito do papel de cativa no castelo, que lhe provocava angústia e medo, os livros a consolavam na frieza do ambiente:

Enquanto esperava, resolveu visitar o castelo. Não pode deixar de admirar sua beleza. Qual não foi sua surpresa, porém, quando encontrou uma porta sobre a qual estava escrito: Aposentos de Bela. Abriu-a num impulso e ficou fascinada com a magnificência que ali reinava. O que mais chamou sua atenção, porém, foi um grande armário de livros, um cravo e vários livros de música. [...] Abriu o armário e viu um livro em que estava escrito com letras douradas: Vossos desejos são ordens. Aqui, sois a rainha e a senhora (TATAR, 2004, p. 75-76).

Em Felicidade clandestina, Lispector apresenta uma menina leitora, narrando-a em meio às ruas de Recife com seu desejo de ler a primeira obra de Monteiro Lobato para crianças. A proprietária do livro As reinações de Narizinho, filha do dono de uma livraria, diante da solicitação do empréstimo da obra, se mostra cruel e vingativa, adiando de forma perversa, tortuosa e humilhante a promessa do empréstimo do livro. Na ânsia de ter o livro nas mãos, a adolescente se submete aos maus-tratos até garantir, por meio da mãe da proprietária, a obra em suas mãos, tomando-a como um desejo consumado:

Eu estava estonteada, e assim recebi o livro na mão. Acho que eu não disse nada. Peguei o livro. Não, não saí pulando como sempre. Saí andando bem devagar. Sei que segurava o livro grosso com as duas mãos, comprimindo- o contra o peito. Quanto tempo levei até chegar em casa, também pouco importa. Meu peito estava quente, meu coração pensativo. Chegando em casa, não comecei a ler. Fingia que não o tinha, só para depois ter o susto de o ter. Horas depois abri-o, li algumas linhas maravilhosas, fechei-o de novo, fui passear pela casa, adiei ainda mais indo comer pão com manteiga, fingi que não sabia onde guardara o livro, achava-o, abria-o por alguns instantes. Criava as mais falsas dificuldades para aquela coisa clandestina que era a 
felicidade. A felicidade sempre ia ser clandestina para mim. [...] Às vezes sentava-me na rede, balançando-me com o livro aberto no colo, sem tocá-lo, em êxtase puríssimo (LISPECTOR, 1998, p. 13).

Em seus poemas, Coralina, apesar de não florear sua infância de fins do século XIX, apresentando-se como uma menina feia e rejeitada, quando trata das histórias de Carochinha elege de forma corrente "Meu melhor livro de leitura" como sua obra afetiva da infância ${ }^{3} 3$. Apresenta a obra para ao leitor poetizando-a em detalhes. Narra, além da cultura material do livro, suas identificações com cada personagem dos contos:

Minhas histórias de Carochinha, meu melhor livro de leitura, capa escura, parda, dura, desenhos preto e branco.

Eu me identificava com as estórias.

Fui a Maria e Joãozinho perdidos na floresta.

Fui a Bela Adormecida no Bosque.

Fui Pele de Burro. Fui companheira de Pequeno Polegar e viajei com o Gato de Sete Botas. Morei com anõezinhos.

Fui a Gata Borralheira que perdeu o sapatinho de cristal na correria da volta, sempre à espera do príncipe encantado, desencantada de tantos sonhos nos reinos de minha cidade

(CORALINA, 1987, p.62)

Com os três recortes literários apresentados, temos inúmeros caminhos para refletir sobre livros e leitores, no entanto, vamos nos ater ao tema proposto. Diante do tempo de cada produção, século XVIII, fins do século XIX e primeira metade do século XX, poderíamos correr riscos de fazer uma análise anacrônica, homogeneizando o tempo histórico. Mas quero destacar aqui algumas questões que podem nos ajudar a pensar, respeitando as especificidades de cada fazer literário, o acesso ao livro, de forma não escolar.

Uma é a relação afetiva com os livros, sendo que esses objetos não foram impostos pelo ambiente escolar, mas sim vivenciados em outros espaços, como o ambiente doméstico, mesmo em um papel de cativa como o de Bela. Outra observação é a opção natural das personagens, sem interferência de adultos, pelo livro, fato que toca em possibilidades de aparentes protagonismos infantil e juvenil. O livro usado como entretenimento é outro aspecto a ser anotado nas produções das escritoras, ou seja, o objeto serviu para puro lazer das meninas, fato demostrado nas linhas dos textos literários, conforme as citações dos fragmentos inseridos. 


\section{CRUZANDO AS PÁGINAS NAS CONSIDERAÇÕES FINAIS}

No meu tempo e lugar, meu olhar recai em uma defesa quase intransigente dos livros nas mãos das crianças ${ }^{4}$. Usando argumentos que se distanciam de práticas e de ações de benevolência, como as famosas campanhas de arrecadar livros velhos e usados para doações, o direito aqui não se confunde com gesto de piedade, caridade e outros aspectos ${ }^{5}$.

Também não argumento favoravelmente ao acesso ao livro como objeto didático, que ensina por meio do texto o verbo de ligação, o substantivo derivado, o predicado nominal e outros. Qualquer fenômeno artístico como a literatura é totalmente passível de escapar dos padrões fixos. Neste aspecto, os livros literários estão propensos muito mais para uma ruptura de normas do que para ser aquietados em redundantes receitas pedagógicas.

Não me parece a melhor opção oferecer o livro com o intuito de moralizar, de descobrir (adivinhar) o que o autor ou autora quis dizer, de tirar lições positivas, de reproduzir as ilustrações de forma seriada (cópia), de fazer do livro um objeto de não intervenção, de não interpretação individual e de grupo, de não socializar as descobertas ou de ter um livro somente como objeto de consumo. Assim como não vejo o livro, isolado, como salvador do conhecimento e da humanidade.

A literatura como direito básico vai para outros caminhos. Um deles é o papel humanizador dos escritos literários, que, a despeito de não ser palpável, de não ser possível avaliar em uma prova e impossível de mensurar rapidamente, é de uma grandeza sem igual. A literatura é fator indispensável de humanização, pois não é hermética, não é determinista e fornece possibilidades de pensarmos as contradições em diferentes realidades e situações.

Humanizar, sensibilizar, não tem idade, e é papel do adulto proporcionar e oferecer às crianças instrumentos que as façam pensar, com suas compreensões próprias, um mundo mais afinado e sem disparidades de direitos universais. Uma sociedade na qual a extensão dos direitos não se limite para os que, historicamente, defendem direitos de poucos tendo como critério classe social, etnia, idade, gênero e modelos indicadores legitimadores de que alguns são mais iguais que os outros, então os menos iguais merecem ações pontuais caritativas.

Aí talvez valha experimentar, proporcionar o livro ao alcance das mãos infantis, desafiando leituras diversas feitas com o olhar, com o coração e com a sensibilidade própria da infância. Nas páginas oferecidas e viradas lentamente, ou apressadamente, coletivamente, ou solitariamente. Deixar, poeticamente, como a criança sabe fazer, os braços curtos abraçarem as 
capas que abraçam as folhas, narizes encostarem-se nas páginas buscando cheiros dos cenários, levar embaixo do sovaco, nas costas, no carrinho e em outros espaços, poderia proporcionar mais Belas, Coras e Clarices nas relações afetivas com os livros?

Oferecer diferentes formatos de livros, com cores variadas ou limitadas, de gêneros possíveis e impossíveis, de autores conhecidos e desconhecidos, de editoras grandes e pequenas. Trazer leituras que podem correr de forma inspiradora, desavisada, sem pragmatismo, que possa provocar diversão, humor, folgança, broma, chacota, tristeza, saudade, curiosidade, lágrimas, risos, desejos, sensações próprias de cada um em seus dias, luas, estações, climas, afinando suas emoções em seus modos de compreenderem o mundo. Nestes aspectos, o livro poderia assumir um formato atrativo como os brinquedos.

Aposto no direito de ter livros no ambiente escolar, livros coletivos ao alcance de todos, ler coletivamente, meninos e meninas aprendendo a dividir, emprestar, doar e compartilhar letras, páginas e a vida. Também estendo o direito à promoção de livros em todos os lugares da casa, no quarto, no banheiro, na estante, fora da estante, em caixas, em baús (como tesouros), no jardim ou na varanda (como plantas). Livros nas praças para a criança que, cansada de correr, deita na grama para vê-los. Nos pontos de ônibus, nas geladeiras que abrigam alimentos livrescos, no lugar de cortar cabelo, nos quartos frios de hospitais, em reuniões familiares ou em qualquer local que reúna a pequenada.

Suponho, por fim, que os livros, em seus silêncios, podem contar tanta coisa. Ou podem ocultar e não contar. Podem trazer e levar emoções, acalmar angústias. Podem ser agradáveis, podem ser agressivos, medonhos. Podem ser muito, pouco, grandes, pequenos, largos, justos, sisudos, divertidos, sem graça, graciosos. Pode ser, mas estes sentimentos, assim como outros, serão construídos quando nós, adultos, garantirmos o direito ao acesso ao livro para as crianças. Elas, nas suas subjetividades, encontrarão seus mundos, seus objetos, personagens, etc. Com os livros em mãos. 
RIGHT TO CULTURAL GOODS IN CHILDHOOD: THE LITERARY BOOK AS AN INTELLECTUAL AND AFFECTIVE INSTRUMENT

ABSTRACT:This text will discuss the relationship between childhood and literature in its aesthetic and artistic nature, as a social good, as a right of all children regardless of age, social class, ethnicity and others. It is intended to bring, for the debate, movements considered proper to childhood that do not include the literary book in the daily life, naturalizing it as a "serious" and distant object of infantile vivacity. Attention is also paid to the pragmatic aspects that involve literary doing, validating objective actions, with deterministic and moralistic effects. In this sense, the right to the book becomes diluted under the effects of an object seen as a redeemer and less as an interaction in a diverse and contradictory movement in the world of the child.

KEYWORDS: Book. Literature. Childhood. Right. Social good

DERECHO A LOS BIENES CULTURALES EN LA INFANCIA: EL LIBRO LITERARIO COMO INSTRUMENTO INTELECTUAL Y AFECTIVO

RESUMEN: Este texto discutirá la relación de la infancia con la literatura en su naturaleza estética y artística, mientras que un bien social, como un derecho de todos los niños a pesar de la edad, clase social, etnia y otros. Se pretende traer, para el debate, movimientos considerados propios de la infancia que no incluyen el libro literario en el cotidiano, naturalizándola como un objeto "serio" y distante de la vivacidad infantil. Se da atención a los aspectos pragmáticos que involucran el hacer literario, validando acciones objetivas, con efectos deterministas y moralistas. En este sentido, el derecho al libro se diluye bajo los efectos de un objeto visto más como redentor y menos como interacción en un movimiento diversamente complejo y contradictorio en el mundo del niño.

Palabras Clave: Libro. Literatura. Infancia. Derecho. Bien social

\section{NotAs}

10 conceito de criança adotado neste texto é o mesmo referenciado pelo Estatuto da Criança e do Adolescente, que a define como toda pessoa até 12 anos de idade.

2 Sobre este tema, pesquiso, desde o doutorado (2006), as relações históricas estabelecidas na infância com a leitura e o livro, a partir do século XVIII à primeira metade do século XX.

3 Vale ressaltar que Coralina, quando criança, teve grandes dificuldades em decifrar as letras de seu livro de leitura do Barão de Macahubas. Foi punida pela sua mestra 
Silvina com a palmatória. A poetisa, em sua adolescência, manteve uma relação afetiva com os romances da época (fora da escola): "Escola difícil. Dificuldade de aprender. Fui vencendo. Afinal menina moça, depois adolescente. Meus pruridos literários, os primeiros escritinhos, sempre rejeitada. Não, ela não. Menina atrasada da mestra Silvina" (CORALINA, 1987, p. 114).

4 Vale, antes de tudo, anotar que tudo que trouxe neste texto tem por objetivo empurrar o debate, pois o que expus são as impressões vividas como autora de livros para crianças, professora de cursos de licenciaturas em uma universidade pública, que também atua com formação continuada de professoras/es das redes públicas. É neste contexto que tentarei amarrar frouxamente algumas coisas para que seja fácil desatá-las e dar continuidade a elas.

5 Quando se trata de cumprir direitos para a infância e adolescência pobres, é comum estes serem atrelados ao cumprimento de ordens de cunho assistencialista e moralista. O direito ao esporte é mais um argumento para impedir o acesso às drogas, a arte para evitar a ida para as ruas, o lazer para combater o ócio e outros movimentos que priorizam práticas assistenciais e moralistas em detrimento dos direitos de fato.

\section{REFERÊNCIAS}

AGUIAR, F. O direito à literatura no século XXI: uma homenagem a Antonio Candido. In: SEMANA DE CIÊNCIAS SOCIAIS DA USP, 8. 2012. Disponível em: <https:// blogdaboitempo.com.br/2012/05/31/o-direito-a-literatura-no-seculo-xxi-umahomenagem-a-antonio-candido-por-flavio-aguiar/\#prettyPhoto>. Acesso em: 1 dez. 2017.

BENJAMIM, W. Rua de mão única. In: Obras escolhidas II. São Paulo: Editora Brasiliense, 1995.

BRASIL. Estatuto da criança e do adolescente. 7 ed. São Paulo: Saraiva, 1998.

CANDIDO, A. O direito à literatura. In: Vários escritos. Rio de Janeiro: Ed. Ouro Sobre Azul, 1088. p. 171-193.

CORALINA, C. Menina mal amada. In: Vintém de cobre: meias confissões de Aninha. Goiânia: Editora da Universidade Federal de Goiás, 1987. p.114.

. Meu melhor livro de leitura. In: Vintém de cobre: meias confissões de Aninha. Goiânia: Editora da Universidade Federal de Goiás, 1987. p.62.

LISPECTOR, C. Felicidade clandestina. Rio de Janeiro: Rocco, 1998.

MACHADO, A. M. Fugindo de qualquer nota: algumas notas sobre ilustração brasileira de livros infantis. In: OLIVEIRA, R. de. Pelos jardins Boboli: reflexões sobre a arte de ilustrar livros para crianças e jovens. Rio de Janeiro: Nova Fronteira, 2008. p. 13-28. 
MINDLIN, J. E. Apresentação à edição brasileira. In: FEBVRE, Lucien; MARTIN, Henri-Jean. O aparecimento do livro. São Paulo: Editora Universidade Estadual Paulista; Hucitec, 1992. p. 1-4.

NUNES, L. B. Livro, a troca. 1989. Disponível em: <http://www.casalygiabojunga.com. br/pt/obras.html>. Acesso em: 5 dez. 2017.

ROCHA, R. Os direitos das crianças. São Paulo: Salamandra, 2014.

SOUZA, R. J. de; MARTINS, I. A. Educação infantil e literatura: um direito a sonhar, ampliar e construir repertório. Conjectura: Filosofia e Educação, Caxias do Sul, v. 20, n. especial, p. 221-239, jan./mar. 2015

TATAR, M. Contos de fadas. (Edição comentada \& ilustrada). Rio de Janeiro: Jorge Zahar Editor, 2004.

Diane Valdez: Professora da Faculdade de Educação da Universidade Federal de Goiás (FE/UFG), mestra em História pela UFG e doutora em Educação (História e Filosofia da Educação) pela UNICAMP.

E-mail:ufs.valdez@gmail.com 